\title{
OBITUARIO
}

\section{José María Blázquez Martínez, un historiador de la Antigüedad}

De mi preceptor: el no haber sido de la facción de los Verdes ni de los Azules, ni partidario de los parmularios ni de los escutarios; el soportar las fatigas y el tener pocas necesidades; el trabajo con esfuerzo personal y la abstención de excesivas tareas, y la desfavorable acogida a la calumnia Marco Aurelio, Meditaciones, I, 5.

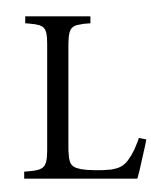

a historiografía de la Historia Antigua en España es incomprensible sin la figura de José María Blázquez. Por una parte fue, en gran medida, el responsable de la configuración de su plantel profesional en el último cuarto del siglo XX y, por otra, su amplísima obra inundó la práctica totalidad de los temas relacionados con la investigación. Algunos rasgos de su personalidad ayudan a comprender no solo su proyección internacional -es, sin lugar a dudas, el estudioso español más citado en el extranjero-, sino también su peso específico en la materia.

Aunque realizó estudios de Filología Clásica en Salamanca, pronto orientó sus intereses hacia la Arqueología y la Historia Antigua. Ambas disciplinas carecían de estudios propios en la universidad española. De hecho, las escasas cátedras que afectaban a ese conocimiento eran de Prehistoria, Historia Antigua y Medieval. La masificación de 


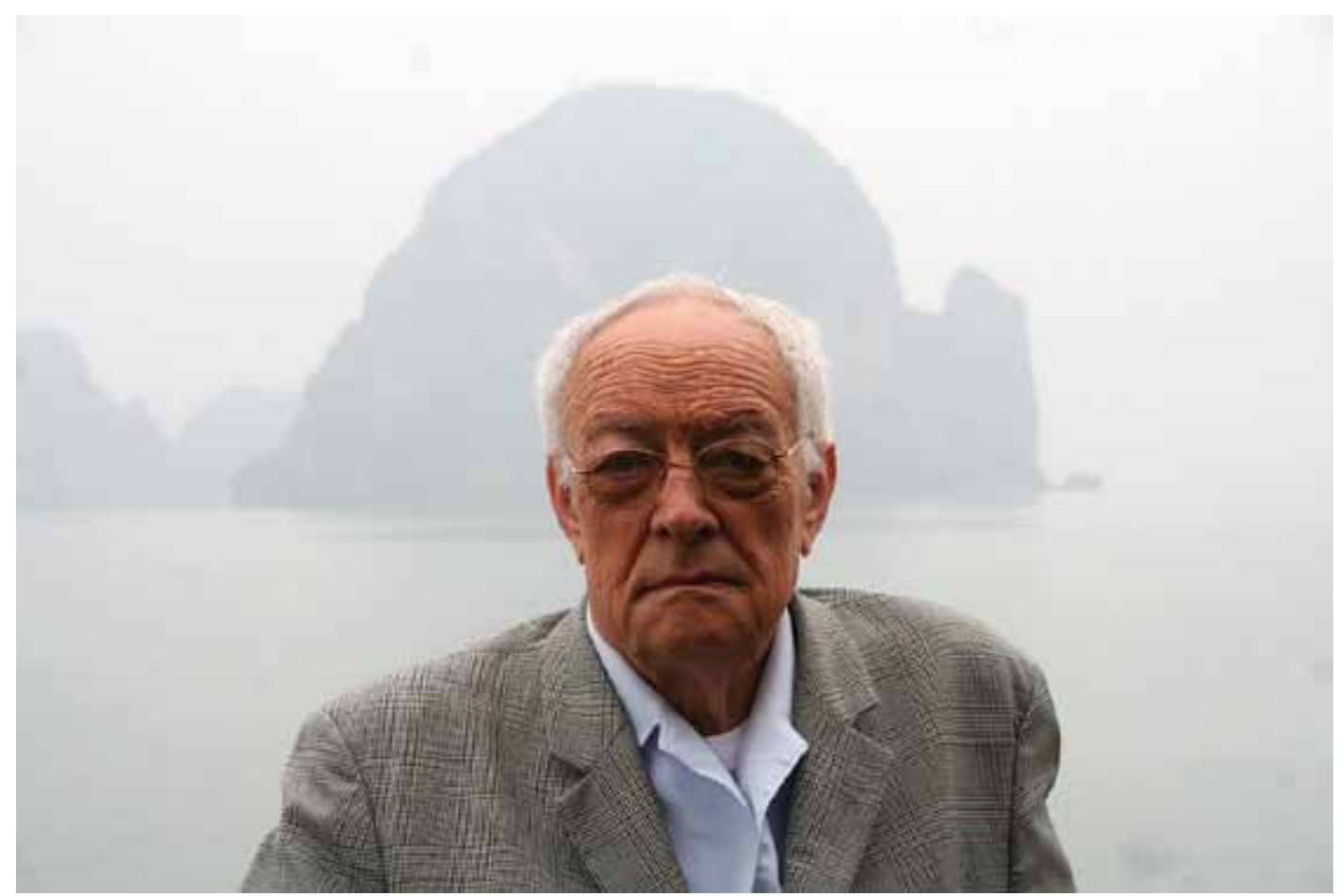

JOSÉ MARÍA BLÁZQUEZ MARTÍNEZ. Oviedo 7 de junio de 1926 -

Madrid 27 de marzo de 2016. / Foto: Jaime Alvar

la Universidad en el tardofranquismo permitió la creación de un ámbito propio para la Historia Antigua, lo que conllevó una nueva regulación de sus estudios y la dotación de plazas de profesores.

En los inicios de este proceso solo había cinco catedráticos del área: Santiago Montero, Ángel Montenegro, Francisco Presedo, Marcelo Vigil y José María Blázquez. Estaban en todos los concursos y, junto a ellos, representantes de las denominadas materias afines, como Prehistoria, sustancialmente representada por Francisco Jordá, o Historia Medieval, con el omnipresente Luis Suárez. Por motivos dispares, ideológicos y de personalidad, aquellos tribunales con frecuencia cuajaban mayorías favorables a Blázquez y sus discípulos. Los primeros procedían de la Filología Clásica, pero desde finales de los 70 empezaron a situarse los que ya cursaban la especialidad de Historia Antigua. La 
reivindicación del área frente a los filólogos tendría repercusiones diversas que ahora no viene al caso analizar. Sin embargo, hay un extremo que no debe soslayarse. Los nuevos profesionales procedentes de la Historia Antigua carecían de las herramientas básicas dominadas por los filólogos clásicos y la propia disciplina no había asumido el rigor característico de la tradición europea.

Entendió Blázquez que la única manera de mejorar la formación era, como había hecho él mismo en Marburg y en Roma, imponer en sus discípulos largas estancias en el extranjero. Fue infatigable en la búsqueda de financiación para ellos, los situó en centros de prestigio y el retorno les estaba casi asegurado con plazas en las oposiciones siguientes. Excelentes profesionales de otras universidades fueron víctimas injustas de un proceder que amparaba el sistema. No pasan los años en balde y las heridas son cada vez menos perceptibles en el gremio, pero han sido causa de mucho dolor. En este sentido, la realidad actual es radicalmente diferente y el recuerdo de aquellos episodios son para los jóvenes batallas lejanas que ya no les conciernen. La muerte contribuye de forma eficaz a la desactivación de aquellos sufrimientos.

El manto protector de Blázquez con frecuencia dio cobijo a discípulos ajenos. $\mathrm{Mu}-$ chos encontraron en él el apoyo necesario para completar su formación en el extranjero, para colocar sus artículos en revistas prestigiosas o para lograr mayorías que los hicieran funcionarios.

Es importante el conocimiento cabal de aquel período de la Historia Antigua, porque ayuda a comprender la propia construcción historiográfica de una disciplina nueva, sino incluso los resultados de la producción académica. La inteligencia de algunos colegas ha permitido registrar testimonios relevantes en este sentido que van viendo la luz de formas dispares.

El Instituto de Historiografía va a poner a disposición de los interesados en su página web el testimonio oral recogido por Fernando Wulff en el que sonsaca a los padres fundadores información reservada al espacio íntimo. El objetivo es crear una sección 
específica con grabaciones y textos transcritos que soporte la memoria vívida de los profesionales de la asignatura y que sirva de ejemplo para otras.

Desde un punto de vista historiográfico es importante reconocer que Blázquez renovó el conocimiento sobre el mundo tartésico y la colonización fenicia de Occidente. Desbordó los tímidos intentos de Antonio Blanco y se convirtió en el referente indiscutible durante décadas. Blázquez fue pionero en el análisis de la aculturación religiosa, firme abanderado de una profunda semitización de las aristocracias tartesias, motor cultural de la primera monarquía peninsular. Ciertamente su percepción del fenómeno, allá por los años 60 y 70 del siglo pasado, estaba ahormada en el paradigma difusionista y colonialista. Sin embargo, cuando triunfaba en la investigación el viento del "milagro" griego, Blázquez sostenía tozudo y contracorriente la prevalencia no solo cronológica, sino de influjo cultural en Occidente, de los fenicios. El supuesto periplo contenido en la Ora Maritima de Avieno no sería griego, sino fenicio; todos los indicios procedentes del Egeo en las estelas decoradas y los materiales arqueológicos de origen griego anteriores al siglo VII habrían llegado de la mano de los fenicios como objetos de comercio. En definitiva, el proceso de estatalización en la Península Ibérica habría sido consecuencia de la presencia de los fenicios. Así pues, los griegos, en la reconstrucción mental que se hacía de la Protohistoria Peninsular, solo habrían tenido relevancia tras los logros perpetrados por los fenicios.

Es cierto que su propuesta solo afectaba a los agentes, no a los modelos interpretativos, pero se acondicionaba a los nuevos tiempos, autoctonistas primero, postcolonialistas después, sin llegar a abandonar su profundas convicciones difusionistas, en un discurso que a cualquiera, excepto a él, hubiera incomodado por contradictorio e incongruente. Jamás los modelos teóricos le supusieron un quebradero de cabeza.

Otro tanto cabría decir a propósito de la religión prerromana, asunto en el que fue pionero y que no abandonó a lo largo de toda su actividad investigadora. Asumido el principio de que los teónimos están relacionados con la función desempeñada por la divini- 
dad, desarrolló el postulado hasta límites insospechados. Un radical era luz absoluta para interpretar los entresijos de las creencias de cualquier comunidad. No había ni matices ni matizaciones. Si se argumenta con radicales no se puede ser mojigato. ¡Cuánto esfuerzo ulterior para devolver teónimos a su condición de topónimos! Pues similar al requerido para comprender que las expresiones epigráficas del siglo III no tienen por qué ser manifestaciones de resistencia a la romanización, sino una modalidad local de ese proceso.

¿Romanización? Buena montura para cabalgar sin freno. Aculturación, resistencia, asimilación, rechazo, semitización, persistencia, cualquier neologismo o innovación conceptual se convertía en recurso excelente para ordenar citas textuales y materiales arqueológicos de la manera requerida por la novissima ars. Legión llegaría después para mostrar las inconsistencias y reelaborar el discurso de modos distintos, pero siempre Blázquez en el horizonte.

Mientras los demás debatían sobre sesudos contenidos, Blázquez -o mejor dicho Bea, su esposa, y más tarde, ya en la Academia, Asun- había hecho centenares de fotocopias y había situado sus artículos en manos de los investigadores más punteros, reconocidos y prestigiosos que, cuando necesitaban poner ejemplos de minería hispanorromana, de aculturación religiosa en el NO. o los períodos de la conquista romana de Hispania, citaban sistemáticamente como única fuente de saber a Blázquez.

Prácticamente hurgó por todos los rincones de la Historia Antigua. Se interesó, además de los asuntos ya mencionados, de un modo especial por los problemas económicos y sociales del Bajo Imperio y poco a poco fue abarcando todos los límites de la Tardoantigüedad, como bloque histórico específico, desde la crisis del siglo III hasta la figura de Mahoma.

Conocía bien las fuentes, su prodigiosa memoria le permitía traerlas a colación en cualquier circunstancia para apuntalar su opinión. A pesar de su firme convicción religiosa, estaba radicalmente persuadido de la escasa intervención divina en la cons- 
trucción de la Iglesia primitiva y que la lucha por el dogma con frecuencia no tenía motivaciones más serias que cualquier reyerta callejera. Los ojos atónitos del auditorio lo embravecían en el discurso iconoclasta, escandaloso y ajeno a los usos académicos.

Confeccionó manuales, en solitario o con discípulos, sobre Oriente, Grecia, Roma, la Península. Impartió conferencias por todas las universidades españolas y una buena cantidad de europeas y americanas. Defendió los resultados de sus investigaciones por congresos de todo el mundo. Consiguió que la disciplina de la Historia Antigua española fuera internacionalmente reconocida y que los estudiosos españoles tuvieran un espacio homologado con el de sus colegas procedentes de cualquier otra escuela o tradición historiográfica. Su esfuerzo fue titánico y, en buena medida, reconocido.

En efecto, logró la cátedra en la Universidad de Salamanca, de donde se trasladó a Madrid. Fue Miembro de la Real Academia de la Historia, Miembro Ordinario del Instituto Arqueológico Alemán de Berlín, de la Hispanic Society of America, y Correspondiente de la Academia Nazionale dei Lincei de Roma. Recibió, además, el doctorado Honoris Causa por las universidades de Bolonia, Salamanca, Valladolid, León y Carlos III de Madrid.

El coloso de la Historia Antigua vivió satisfecho la vida que le tocó vivir. No ambicionó nada desproporcionado; la envidia no formaba parte de su mapa emocional. Rara vez hablaba mal de los colegas, aunque hacía chanza de todo, empezando por sí mismo. Le gustaba saber de la gente y disfrutaba con cierta malicia pregonando los presuntos secretos que sus redes informativas le proporcionaban. Se sabía epicentro de un determinado escenario y representaba con autoridad y solvencia su papel, del que disfrutó hasta la última gota.

Jaime Alvar

Director 